\title{
TERRITORIAL RESILIENCE: AN ECONOMIC PERSPECTIVE
}

\author{
Antonescu Daniela ${ }^{1}$, Ciocănel Bogdan ${ }^{2}$ \\ ${ }^{1}$ Institute of National Economy, Romanian Academy (ROMANIA), ${ }^{2}$ CIT - IRECSON (ROMANIA) \\ daniela.antonescu25[at]gmail.com, bogdan.ciocanel[at]irecson.ro
}

\begin{abstract}
During periods of economic growth or crisis / recession, territorial inequalities are becoming more acute. Thus, periods of economic growth determine prosperity for almost all regions, in varying proportions (as a rule, less developed regions benefit more from growth compared to developed ones), while in times of crisis the more developed regions recover more heavily than the least developed, requiring more time to reach the initial level (pre-crisis).

The recent global financial crisis has prompted the emergence and promotion of a concept that has also prompted the interest of decision-makers and academics. This concept is called economic resilience and represents "the capacity of a system to resist, absorb or overcome an internal or external economic shock". This interest is also supported by the need to promote solutions and measures to reduce the negative effects of the crisis or economic recession as quickly as possible. Although there is an opinion that the 2008 crisis has ended, not all NUTS-2 regions of the EU-28 have rebounded after the economic downturn. This article aims to invalidate or confirm the subsequent claim by analyzing two indicators relevant for regional performance assessment: GDP per capita and Employment rate. The disaggregated spatial analysis highlights the more nuanced impacts of the crisis. The varied temporal and spatial geography of the crisis raises interesting questions about the relative performance of the regions from the perspective of the two indicators.
\end{abstract}

Keywords: Resilience, Regions, Territorial Inequalities

\section{INTRODUCTION}

At the territorial level, economic processes do not have a steady evolution and trigger specific, politicallyoriented, territorially-localized reactions, which may have certain amplitudes on longer or shorter period of time. The evolution and cyclicality of certain economic phenomena are well known in the economic theory. Cycles are determined by the mechanism of the economy and are repeated with certain regularity. The economic cycle is a form of economic activity, the moment when the economy goes through several phases, returning to the initial phase. These phases are: the crisis (the point at which growth ceases and the recession begins), the recession (the phase in which there is a continuous reduction of economic activity) refreshing (the phase in which the resumption of production and revenue growth takes place) and the expansion (there is a high increase in the national product, in the demand for labour, etc.). After a period of economic growth, there is usually a period of global or regional crisis, which must be overcome.

The process of resuming economic growth after a period of crisis has been referred to as "resilience", becoming more relevant in understanding the causes of the current global crises and in supporting / promoting certain models of uneven, national or regional development.

At present, the analysis of the different forms of resilience and the capacity of some territorial systems (regions, urban areas, cities, etc.) represent a particular interest, especially from the perspective of regional economy theory. At EU level, this is all the more amplified by the fact that there are, besides local and national actions, a series of instruments originally intended for cohesion and convergence, which have also played an important role and the resilience of regions after the 2008 crisis.

In view of the above, the article analyzes how the resilience phenomenon is viewed and interpreted from the perspective of the regional economy and, in the conditions of competitive markets, under different political influences, taking into accounts the different endogenous capacities and potential at the territorial level. We consider that the topic of resilience is of interest to the regional economy because some areas present a series of internal and external transformation tendencies, which often occur in the 


\section{\#3/2018 URBAN CHALLENGES}

form of challenges requiring rapid reaction. Under these conditions, some cities can adapt better and faster to crisis situations, they can recover faster, while others face structural changes, unemployment, migration, company bankruptcies, etc., which ultimately lead, to an inevitable decline and to a difficult and cumbersome recovery. Last but not least, understanding and addressing factors that lead to faster territorial resilience remains an interesting subject.

\section{THE CONCEPT OF TERRITORIAL RESILIENCE (REGIONAL, URBAN)}

The concept of resilience has no generally accepted definition, and in regional studies and analyses it has not been approached frequently due to the lack of statistical data and information.

At origins, the concept comes from French, résilience, which in turn took it from the Latin resilio [1]. defining a leap back and up after an impact with an obstacle or the ability of an entity / system to "recover" its shape and position after certain disruptive actions or after interruptions of evolution. The first to use it were the physicists in their attempt to show the metal's property to resist shock and their ability to return to their original state [2].

Subsequently, the term was also taken over in other areas such as economics, informatics, biology, aerospace, finance, banking, etc. From the perspective of the regional / urban economy, resilience has been analyzed in particular in the context of the debates on sustainable development and adaptation to current climate change [3]. Initially, territorial resilience was a tool for analyzing the urban challenges posed by major threats and climate disasters [3].

In general, the notion of resilience can be defined and dealt with as:

1. a system response to specific extraordinary events and shocks [3];

2. a stable state of a system at certain interferences;

3. the ability to avoid and manage man-made and nature-induced hazards [4] etc.

4. A "response to impact", a capacity to adapt to situations of uncertainty.

In general, regional economic resilience describes the process of recovery of the area after a series of exogenous shocks. The concept can take different forms depending on the nature of the development process. Ron Martin [5] distinguishes three forms of resilience: of engineering nature focused on balance, ecological and adaptive (complex). One of the most common approaches is to analyze the deviation of GDP or the unemployment rate from the original trend (balance) and the time necessary to return to the starting point $[6,7]$.

In the regional / urban economy, resilience represents the ability of a region / city to tolerate certain disturbances, being preceded by a process of reorganization around new structures [8].

Moreover, resilience can also be defined as:

- the ability of a region / city to anticipate, prepare, respond, and recover after a disturbing phenomenon [9];

- the ability to solve local economic problems in a way that leads to a long-term recovery [3] after recession, increased competition in other areas, major technological changes, etc .;

- the ability of the regional / city economy to maintain a level of pre-existing growth or to return to the previous (pre-existing) level. The level of local growth could be measuring, for example, by: production, employment, population, migration;

- urban resilience is the ability of a city to recover successfully from the shocks produced in its economy, or to recover once it has left the path of growth [7].

Beyond these general definitions, there remains, however, a great deal of ambiguity regarding the concept of regional resilience: first, it should cover both the recovery capacity and the level of resistance 


\section{\#3/2018 URBAN CHALLENGES}

to a shock (this resistance refers to the ability of the area to preserve its structure and function despite emerging disturbances).

Some authors [7] suggest the idea that regional / urban resilience refers to "the extent to which the social structure of the accumulation of territory must be stable over time". Some research has shown that regional / urban resilience is discontinuous over time, because the nature of the shock may change as the structure and nature of the regional economy evolves / transforms (has a dynamic nature).

In a first stage, when regional / urban structures were relatively simple, the territories were more resilient and more stable to shocks than complex ones. Subsequently, this hypothesis has seen a total change, identifying that complex systems are more stable. Starting from the definition of the level of "complexity" and "stability", the analysis of the relationship between the two concepts and the emergence of a new concept, the "elasticity", defined by the capacity of a system to absorb and adapt to disturbances, major structural collapses, etc is reached. Applying the principles of mechanical physics within economic systems has led to the emergence of the concept of economic balance [10]. In a state of balance, any economic system moves to a certain state of balance, the forces and adjustments that take place causing the correction to occur automatically (Figure 1).

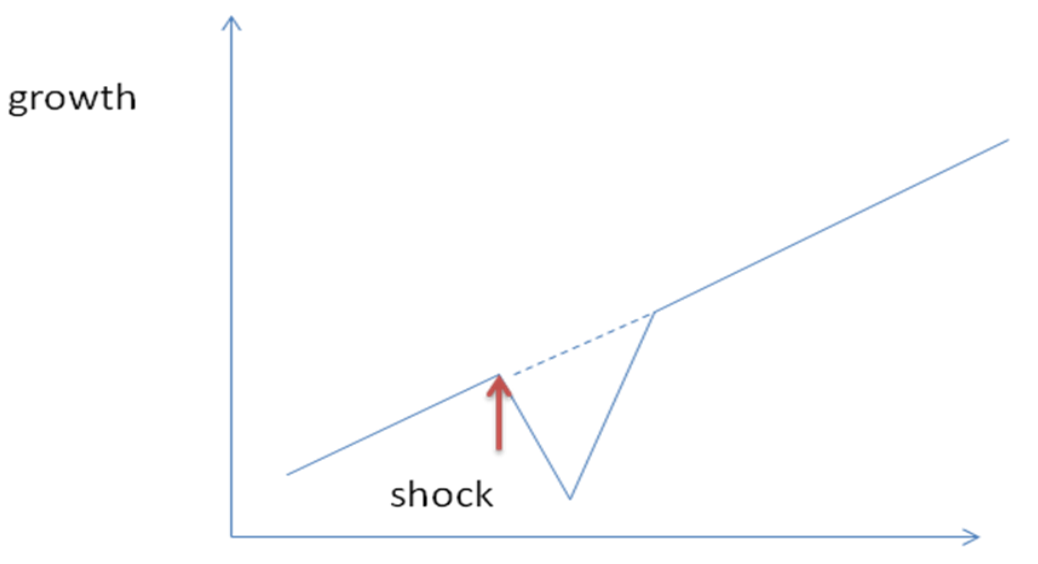

time

Figure 1: Stylised Responses of a Urban Economy to a Shock

Source: [3]

In conclusion, the resilience of different territorial economic systems (urban, regional, local, etc.) can be analyzed (measured) with the help of their sensitivity to shocks and the response time needed to return to their original state. Where regional systems have a complex structure, they can adapt quickly to certain shocks or crises, being able to absorb and receive extreme shocks without significant changes in shape or function. Formed by a multitude of businesses and economic, social companies, universities, research centres, etc., regional systems can quickly recover through innovation. In fact, these crises are, in themselves, a process of cumulative growth, adaptation, or resilience of cities to new global transformations, regardless of their nature.

\section{REGIONAL INEQUALITIES AND RESILIENCE}

Over time, the analysis of regional inequalities has been made on the basis of indicators and techniques of interpretation of certain economic and social phenomena, which have profoundly conditioned the income, the welfare of the inhabitants, the local opportunities, etc. Among the phenomena that have been analyzed and interpreted, we can mention: the level and availability of natural resources, 


\section{\#3/2018 URBAN CHALLENGES}

environmental and geographical features, population growth rate; demographic indicators (health, life expectancy at birth, etc.), the degree of openness of the urban economy and its structure, the size of the internal market, import-export activities, export specialization, social development level, variability of income instability), access to funding sources, governance quality, etc.

The analysis of regional resilience takes into account several possibilities of interpretation [3] as follows:

1. A first possibility is that a regional system has many forms of adaptation to shocks, depending on the nature of the economic structure and their behaviours. The two elements - variety and adaptability, can cause a regional system to be more resilient than another system;

2. Another possibility would be the shock-blocking capability: a regional system is resilient if it has the shock-blocking capacity in the form of a "mechanical resistance" (positive lock);

3. the complex nature of a regional / urban system can be a source of resilience (nature characterized by connectivity, self-organization, etc.).

Starting from the theory of endogenous development [11] identifies resilient territorial systems with those capable of self-renewing and adapting.

A resilient economic system can rely on the economy, institutions and social organizations that can have the following functions:

1. can apply innovations that explore new processes and organizational patterns,

2. use external information, $\mathrm{k}$

3. develop formal and informal networks between people and institutions,

4. implement adaptive and effective development strategies (Table 1).

\begin{tabular}{|l|l|}
\hline \multicolumn{1}{|c|}{ Characteristics } & \multicolumn{1}{|c|}{ Description } \\
\hline The current situation & $\begin{array}{l}\text { This aspect shows the ability to understand and maintain the existing } \\
\text { conditions. Addresses physical facilities existing in the urban area. }\end{array}$ \\
\hline Trends and threats & $\begin{array}{l}\text { It refers to prediction ability based on current information (for example, } \\
\text { scenarios and models for impact and risk assessment in policy making). }\end{array}$ \\
\hline $\begin{array}{l}\text { Ability to learn from past } \\
\text { experiences }\end{array}$ & $\begin{array}{l}\text { Urban resilience is based on past experiences and the ability to use new } \\
\text { knowledge under similar conditions in the future. }\end{array}$ \\
\hline Ability to set goals & $\begin{array}{l}\text { It has the ability to respond to changing issues (eg climate change, risk } \\
\text { management, etc.). Vision exercises involve multi-sectoral collaboration. }\end{array}$ \\
\hline Ability to initiate actions & $\begin{array}{l}\text { Involves authority and decision-makers, along with other stakeholders } \\
\text { (experts, consultancy firms, etc.). }\end{array}$ \\
\hline Ability to involve citizens & Assumes broad public participation in decision-making process. \\
\hline
\end{tabular}

Table 1: The main characteristics of regional resilience

Source: [12]

\section{ECONOMIC RESILIENCE AT REGIONAL LEVEL, IN EUROPEAN UNION (EU-}

28)

The economic crisis refers to evolution of performance through economic indicators of declining or growth. This article will use two relevant economic indicators for analyzing the degree of development and regional performance:

1. GDP per capita is the conventional indicator used to measure the economic downturn, with a recession usually defined as two consecutive negative growth quarters. This indicator provides the strongest measure of long-term effects and outcomes that are appropriate when analyzing resistance. 


\section{\#3/2018 URBAN CHALLENGES}

2. Total occupation. It will analyze the evolution of this indicator from one year to the next, in order to measure the economic decline at regional level.

We will use the Absolute Amplitude, which is the difference between the maximum and the minimum of a series of values and gives us information about the width of the value range on which the data in the series. A series of high amplitude values indicate a stretched range of values due to either large data dispersion or scatter, or simply the fact that there are many values. If two sets of values have the same number of values, but one has larger amplitude, then its values are more scattered. We'll also use Average Values (Arithmetic mean of a series of values), that is a simple and, at the same time, very synthetic indicator, being a very good indication of the value around which data is grouped together. Media is an indicator of central tendency of a series of values, and usually shows which tend to cluster data.

The first indicator analyzed is GDP per capita over the period 2007-2016, at the level of NUTS-2 regions (the NUTS classification - Nomenclature of territorial units for statistics - is a hierarchical system for dividing up the economic territory of the EU). For this indicator, the maximum and minimum values and the arithmetic mean were calculated. For the average, it is clear that it has seen a growth trend since 2012 (compared with 2007, with a low point in 2009). However, it can be seen that after 2008, the maximum decrease after the crisis, the value of the indicator has reduced from 25,308 Euro (2008) to 23,734 Euro (2009), which means that on average the regions recorded decreases in GDP per capita immediately after the crisis. The value of the indicator slightly increases after 2008, and it is only in 2012 that it approaches the one of the year before the crisis. A quite hard recovery (resilience) has been registered after the 2008 crisis in terms of average GDP per capita (Fig. 2, Annex 1).

The minimum figure has not decreased at all throughout the period, while the maximum was recovered in 2012.

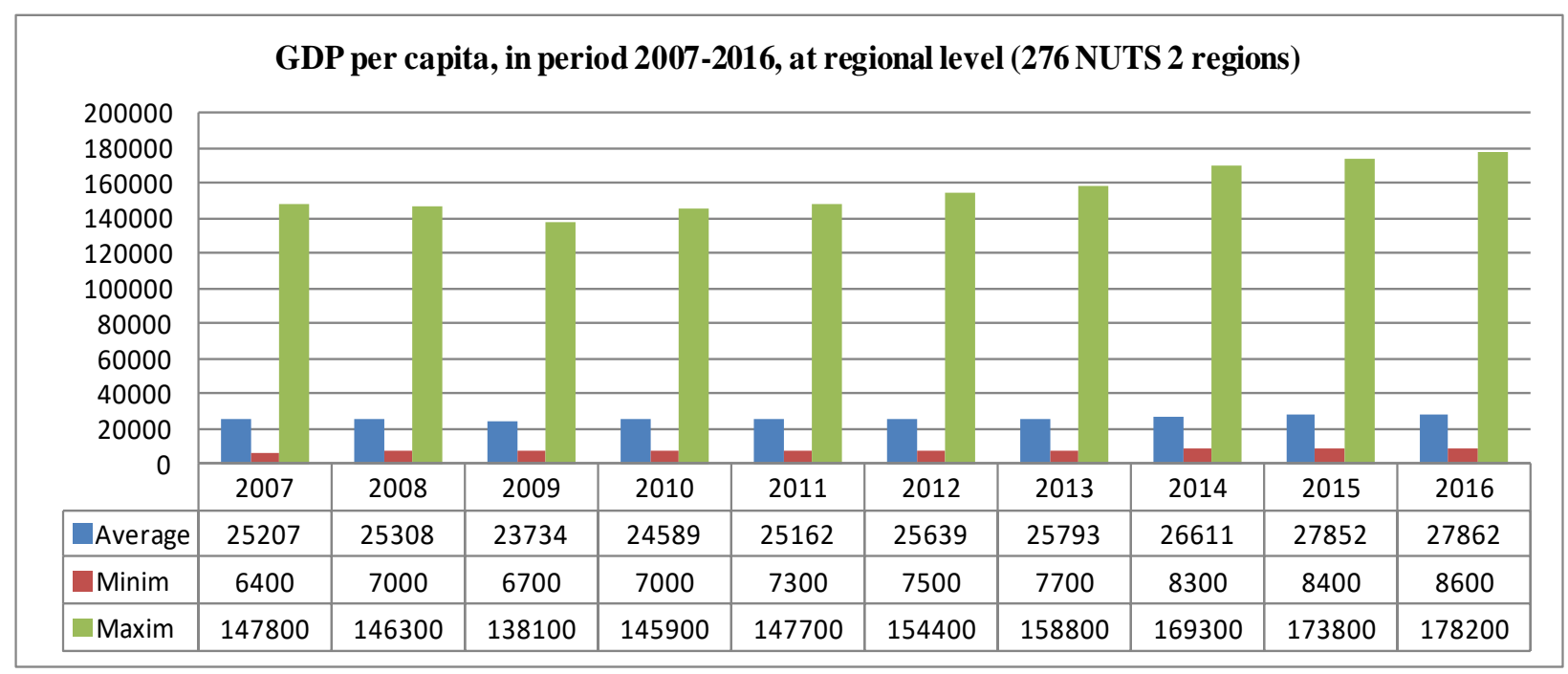

Figure 2: GDP per capita, in period 2007-2016

Source: [13]

Figure 3 shows the average, minimum and maximum per capita GDP, 2016 and 2007 

\#3/2018 URBAN CHALLENGES

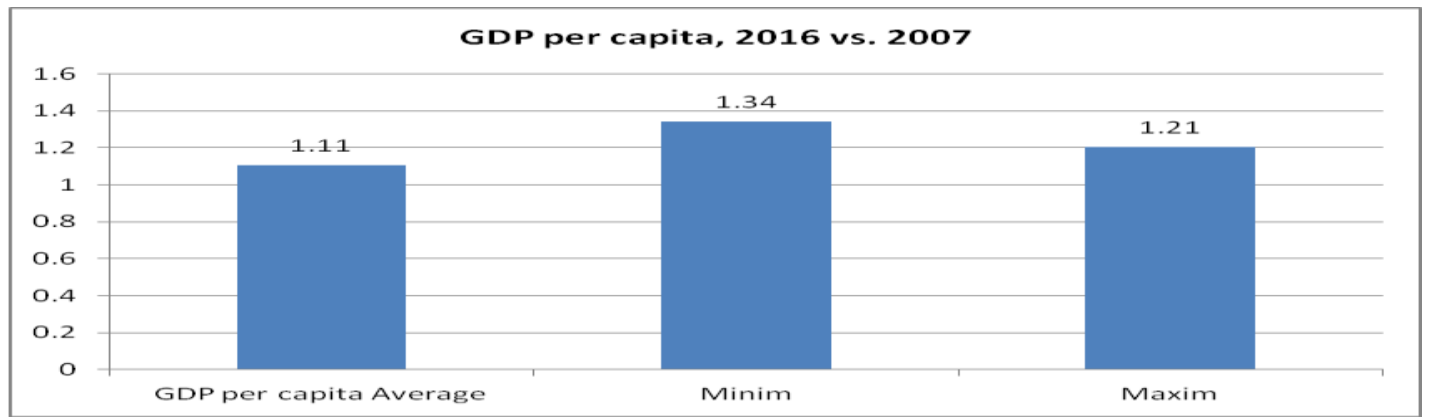

Figure 3. GDP per capita, 2016 vs. 2007 Source: [13]

Regarding the employment rate, it can be concluded that the average value was recovered only in 2010, while the minimum value was not recovered at present. Also, the maximum value was recovered in 2012, after which, in the following year, it fell again below the 2007 value (Fig. 4, Annex 2).

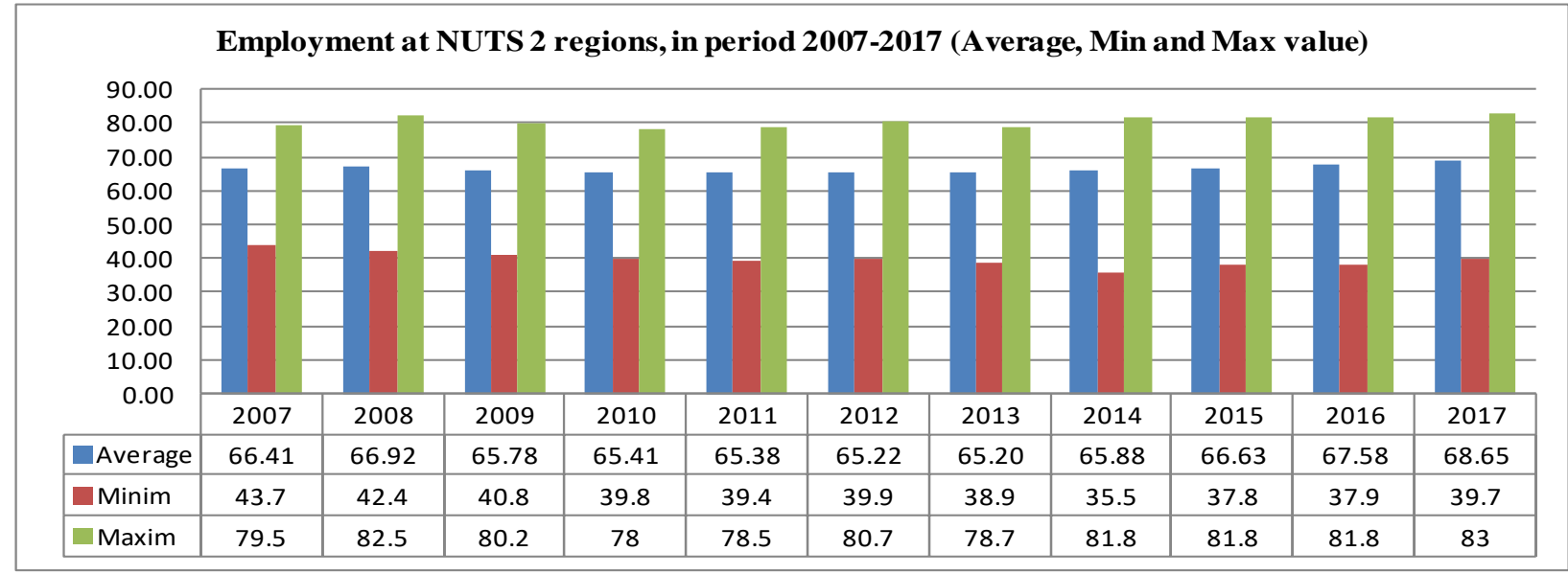

Figure 4. Employment Rate at NUTS 2 regions, in period 2007-2017 Source: [13]

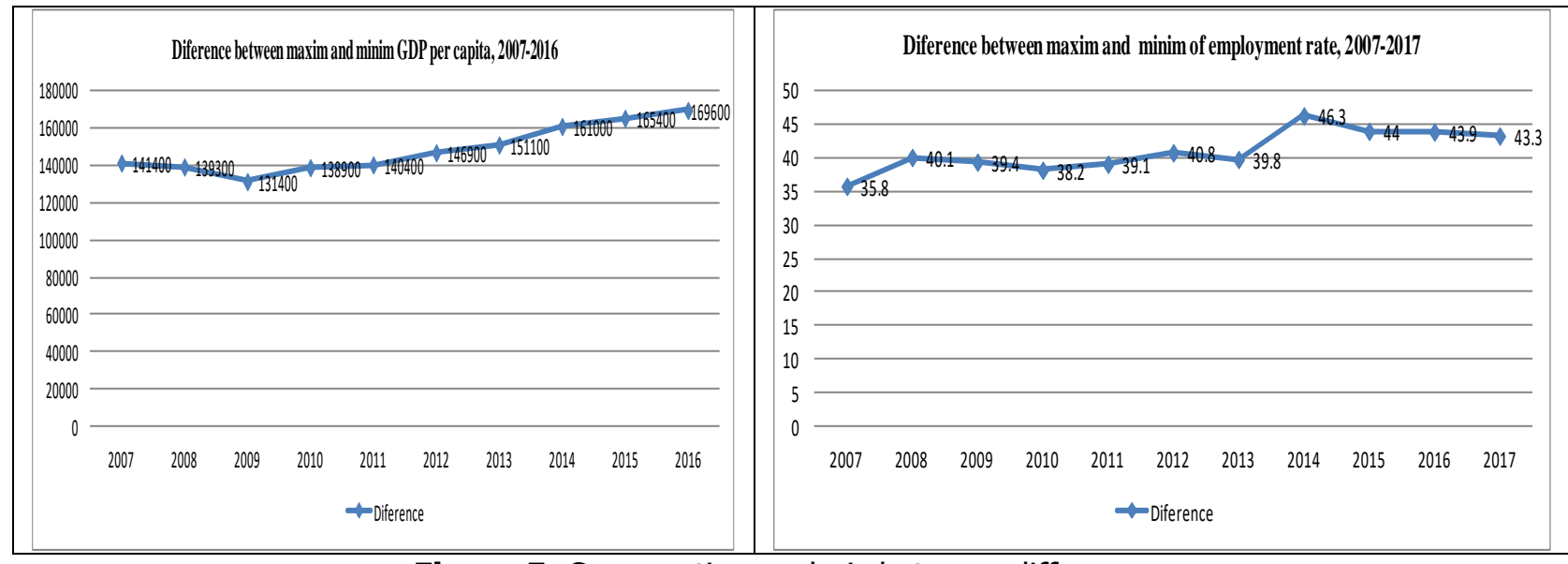

Figure 5. Comparative analysis between differences

Source: [13] 
\#3/2018 URBAN CHALLENGES

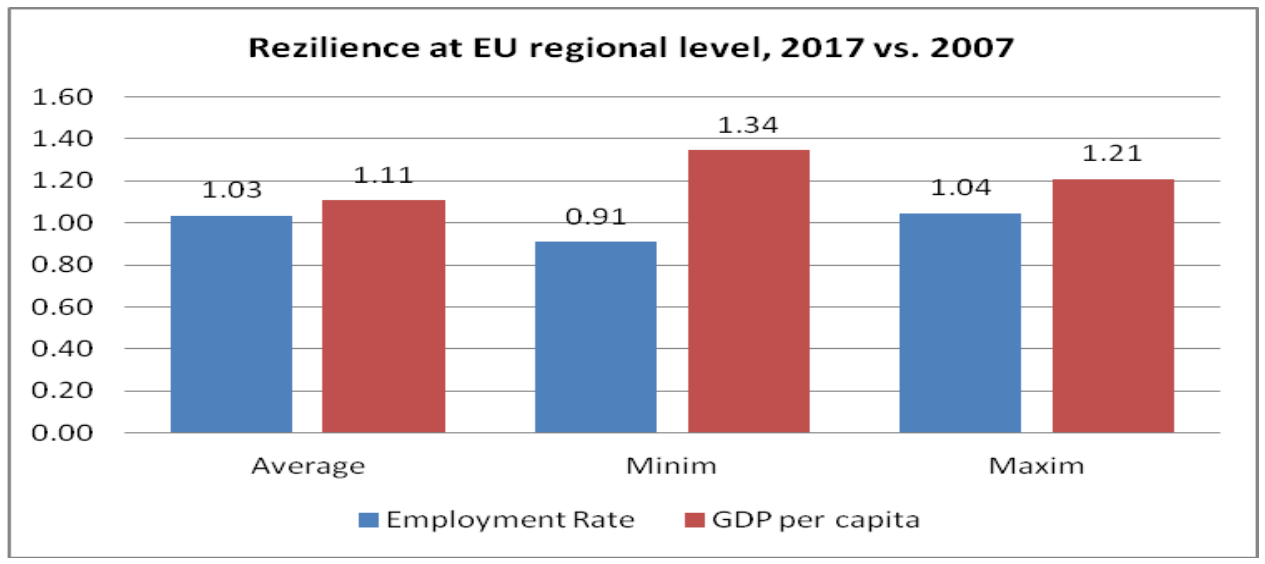

Figure 6: Rezilience at EU regional level, 2017 vs. 2007

Source: [13]

The regions that recovered on average in terms of GDP per capita and employment rate can be grouped as follows :

1. resilient - those regions that have not experienced an absolute decline in economic activity since the crisis;

2. covered - those regions that have experienced economic decline, but have recovered activity before the shock;

3. regions - that have exceeded the recession threshold but have not yet recovered to levels of activity before the shock;

4. regions - that have experienced a decline in economic activity and have not recovered.

\section{CONCLUSIONS}

In general, the concept of urban resilience is perceived as a certain level that cities can tolerate under certain external disturbances. In this respect, territorial resilience is not just a "response to a certain impact", it is the society or economy that can be considered flexible and capable of adapting to uncertainty. Resilience implies the ability of an area to anticipate, prepare, respond, and recover after a certain disturbance. In terms of territorial economic resilience, this is seen as the capacity of an area to solve local economic problems with long-term results.

The way a local economy responds to "external events of the nature of crises or recession" shows how it develops and evolves. Briefly, the regional economic resilience is the capacity of an economy to maintain at a level of growth pre-existing to the shock, to return to the previous level (pre-existing to the shock) to increase or modify the structure of the economy and achieve the previous growth level (at least). The level of resilience can be assessed using a set of indicators, of which the most important are: total GDP per capita, employment rate, demographic indicators, etc.

The empirical analysis of this research study showed that, at the level of the 276 NUTS 2 regions of the EU-28, economic resilience had different connotations. Moreover, it was found that the more performing regions in terms of per capita GDP recovered less than the least developed, while, from the employment point of view, the less developed regions did not recover either in 2017. 


\section{Annex}

\section{Annex 1: Growt Rate of the GDP per capita, during the period 2007-2016 (2007=100)}

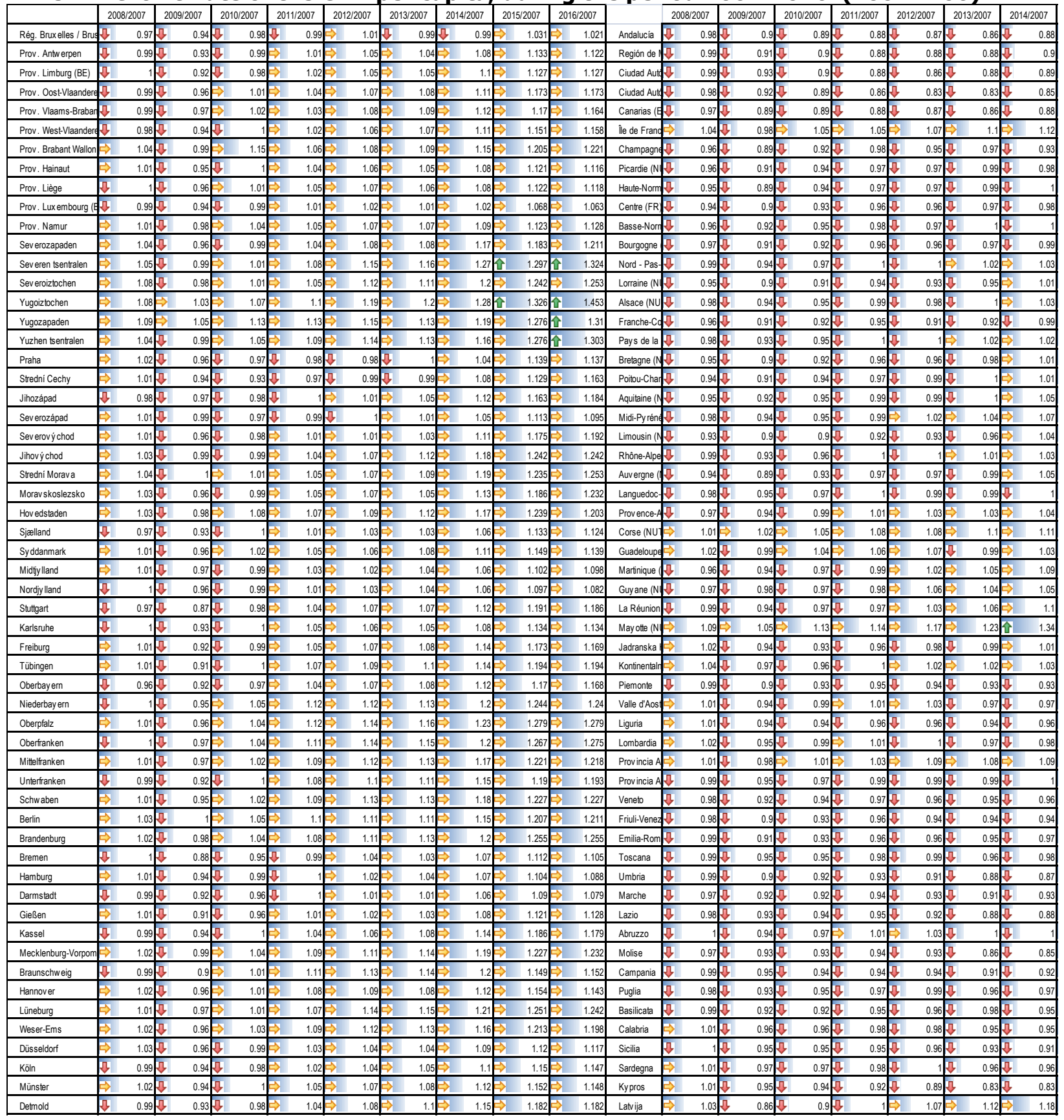

Sources: [13] 

\#3/2018 URBAN CHALLENGES

Annex 2: Employment Rate $(2007=100)$

\begin{tabular}{|c|c|c|c|c|c|c|c|c|c|c|c|c|c|c|}
\hline \multirow{2}{*}{\multicolumn{2}{|c|}{ Rég. Bruxel $\Rightarrow$}} & 2008/2007 & 2009/2007 & 2010/2007 & 2011/2007 & \multicolumn{2}{|r|}{ 2017/2007 } & \multicolumn{2}{|r|}{ 2008/2007 } & 2009/2007 & $2010 / 2007$ & $2011 / 2007$ & 2012/2007 & 2017/2007 \\
\hline & & $1.01 \Rightarrow$ & $1.01 \Rightarrow$ & $1.00 \Rightarrow$ & $0.98 \Rightarrow$ & $0.99 \Rightarrow$ & 1.03 & Jadranska $\vdash \Rightarrow$ & $1.00 \Rightarrow$ & 0.99 & 0.97 \ & $0.93 \sqrt{2}$ & $0.91 \Rightarrow$ & 1.01 \\
\hline Prov. Antwe & & $1.00 \Rightarrow$ & $0.98 \Rightarrow$ & $1.00 \Rightarrow$ & $0.98 \Rightarrow$ & $0.99 \Rightarrow$ & 1.01 & Kontinentaln $\Rightarrow$ & $1.02 \Rightarrow$ & 1.01 ᄃ & 0.97 そ & 0.94 々 & $0.90 \Rightarrow$ & 0.99 \\
\hline Prov. Limbı & & $1.01 \Rightarrow$ & $1.02 \Leftrightarrow$ & $1.02 \Rightarrow$ & $1.03 \Rightarrow$ & $1.02 \Rightarrow$ & 1.07 & Piemonte $\Rightarrow$ & $1.00 \Leftrightarrow$ & 0.98 & $0.98 \Rightarrow$ & $0.99 \Leftrightarrow$ & $0.98 \Rightarrow$ & 1.00 \\
\hline Prov. Oost-' & & $1.03 \Rightarrow$ & $1.01 \Rightarrow$ & $1.01 \Rightarrow$ & $1.01 \Rightarrow$ & $1.01 \Rightarrow$ & 1.02 & Valle d'Aost $\leftrightharpoons$ & $0.99 \Rightarrow$ & 0.98 Б & $0.99 \Rightarrow$ & $0.98 \Rightarrow$ & $0.97 \Leftrightarrow$ & 0.98 \\
\hline Prov. Vlaan & & $1.00 \Rightarrow$ & $0.99 \Rightarrow$ & $0.99 \Rightarrow$ & $1.00 \Rightarrow$ & $1.00 \Rightarrow$ & 1.00 & Liguria & $1.00 \Rightarrow$ & 1.00 द & $0.99 \Rightarrow$ & $0.99 \Rightarrow$ & $0.98 \Rightarrow$ & 0.98 \\
\hline Prov. West- & & $0.99 \Rightarrow$ & $0.98 \Rightarrow$ & $1.00 \Rightarrow$ & $1.00 \Rightarrow$ & $0.98 \Rightarrow$ & 1.03 & Lombardia $\Rightarrow$ & $1.00 \Rightarrow$ & 0.99 द & $0.97 \Rightarrow$ & $0.97 \Rightarrow$ & $0.97 \Rightarrow$ & 1.01 \\
\hline Prov. Braba & & $1.01 \Rightarrow$ & $0.98 \Rightarrow$ & $0.99 \Rightarrow$ & $0.99 \Rightarrow$ & $1.00 \Rightarrow$ & 1.03 & Provincia Al $\Rightarrow$ & $1.01 \Rightarrow$ & 1.01 ら & $1.02 \Rightarrow$ & $1.02 \Rightarrow$ & $1.03 \Rightarrow$ & 1.05 \\
\hline Prov. Haina & & $1.01 \Rightarrow$ & $0.97 \Rightarrow$ & $0.99 \Rightarrow$ & $1.00 \Rightarrow$ & $1.00 \Rightarrow$ & 1.01 & Provincia $A \mid \leftrightharpoons$ & $1.01 \Rightarrow$ & 1.00 Б & $0.99 \Rightarrow$ & $0.99 \Rightarrow$ & $0.99 \Rightarrow$ & 1.02 \\
\hline Prov. Liège & & $1.01 \Rightarrow$ & $1.01 \Rightarrow$ & $1.00 \Rightarrow$ & $1.01 \Rightarrow$ & $1.01 \Rightarrow$ & 0.99 & Veneto & $1.01 \Rightarrow$ & 0.98 Б & $0.98 \Rightarrow$ & $0.99 \Rightarrow$ & $0.99 \Rightarrow$ & 1.00 \\
\hline Prov. Luxer & & $1.00 \Rightarrow$ & $0.99 \Rightarrow$ & $1.02 \Rightarrow$ & $1.01 \Rightarrow$ & $1.02 \Rightarrow$ & 1.05 & Friuli-Venez $\Rightarrow$ & $1.00 \Rightarrow$ & 0.97 Б & $0.97 \Rightarrow$ & $0.98 \Rightarrow$ & $0.97 \Rightarrow$ & 1.00 \\
\hline Prov. Namı & & $0.98 \Rightarrow$ & $0.97 \Rightarrow$ & $0.99 \Leftrightarrow$ & $0.98 \Rightarrow$ & $0.99 \Rightarrow$ & 1.01 & Emilia-Rom: $\Rightarrow$ & $1.00 \Rightarrow$ & $0.97 ら$ & $0.96 \Rightarrow$ & $0.97 \Rightarrow$ & $0.96 \Rightarrow$ & 0.98 \\
\hline Severozapa & & $1.04 \Rightarrow$ & $1.01 \Rightarrow$ & 0.96 乙 & 0.94 反 & $0.94 \Rightarrow$ & 1.01 & Toscana $\Rightarrow$ & $1.01 \Rightarrow$ & 1.00 & $0.98 \Rightarrow$ & $0.98 \Rightarrow$ & $0.98 \Rightarrow$ & 1.02 \\
\hline Severen tse & & $1.03 \Rightarrow$ & $1.02 \Rightarrow$ & $0.97 \Rightarrow$ & $0.96 \Rightarrow$ & 0.97 亿 & 1.12 & Umbria & $1.01 \Rightarrow$ & 0.97 Б & $0.97 \Rightarrow$ & $0.96 \Rightarrow$ & $0.95 \Rightarrow$ & 0.97 \\
\hline Severoiztoc & & $1.04 \Rightarrow$ & $0.99 \Rightarrow$ & $0.95 \sqrt{2}$ & $0.93 \sqrt{\checkmark}$ & $0.92 \Rightarrow$ & 1.09 & Marche & $1.00 \Rightarrow$ & 0.98 & $0.98 \Rightarrow$ & $0.96 \Rightarrow$ & $0.97 \Rightarrow$ & 0.96 \\
\hline Yugoiztoche & & $1.04 \Rightarrow$ & $1.03 \Rightarrow$ & $0.99 \Rightarrow$ & $0.97 \Leftrightarrow$ & $0.98 \Rightarrow$ & 1.10 & Lazio & $1.01 \Rightarrow$ & $1.00 \Longleftrightarrow$ & $0.99 \Rightarrow$ & $0.99 \Rightarrow$ & $0.99 \Rightarrow$ & 1.02 \\
\hline Yugozapade & & $1.04 \Rightarrow$ & $1.03 \Rightarrow$ & $0.97 \Rightarrow$ & $0.95 \Rightarrow$ & $0.95 \Rightarrow$ & 1.05 & Abruzzo $\Rightarrow$ & $1.02 \Rightarrow$ & 0.96 ह & $0.96 \Rightarrow$ & $0.98 \Rightarrow$ & $0.98 \Rightarrow$ & 0.98 \\
\hline Yuzhen tser & & $1.03 \Rightarrow$ & $1.00 \sqrt{2}$ & 0.95 久 & 0.92 ل & $0.94 \Rightarrow$ & 1.11 & Molise & $1.01 \Rightarrow$ & 0.97 Б & 0.95 そ & 0.94 反 & $0.94 \Rightarrow$ & 0.96 \\
\hline Praha & $\Rightarrow$ & $1.00 \Rightarrow$ & $1.00 \Rightarrow$ & $1.00 \Rightarrow$ & $1.00 \Rightarrow$ & $1.02 \Rightarrow$ & 1.09 & Campania $\Rightarrow$ & 0.97 \ & $0.93 \sqrt{2}$ & 0.91 飞 & $0.90 \sqrt{2}$ & $0.91 \Rightarrow$ & 0.96 \\
\hline Stredni Cecl & & $1.01 \Rightarrow$ & $0.99 \Rightarrow$ & $0.99 \Leftrightarrow$ & $1.00 \Rightarrow$ & $1.02 \Rightarrow$ & 1.10 & Puglia & $1.00 \Rightarrow$ & 0.96 द & $0.95 \Rightarrow$ & $0.96 \Rightarrow$ & $0.96 \Rightarrow$ & 0.96 \\
\hline Jihozápad & $\Rightarrow$ & $1.01 \Rightarrow$ & $0.98 \Rightarrow$ & $0.97 \Longleftrightarrow$ & $0.99 \Rightarrow$ & $1.00 \Rightarrow$ & 1.09 & Basilicata $\Rightarrow$ & $1.00 \Rightarrow$ & 0.98 ᄃ & $0.95 \Rightarrow$ & $0.96 \sqrt{3}$ & $0.95 \Rightarrow$ & 1.00 \\
\hline Severozápa & & $1.01 \Rightarrow$ & $0.99 \Rightarrow$ & $0.99 \Rightarrow$ & $1.01 \Rightarrow$ & 1.00 合 & 1.15 & Calabria $\Rightarrow$ & $0.98 \Rightarrow$ & $0.96 \sqrt{2}$ & $0.94 \sqrt{3}$ & $0.94 \sqrt{\checkmark}$ & $0.92 \sqrt{7}$ & 0.91 \\
\hline Severovýcr & & $1.00 \Rightarrow$ & $0.97 \Rightarrow$ & $0.98 \Rightarrow$ & $0.99 \Rightarrow$ & $0.99 \Rightarrow$ & 1.11 & Sicilia & $0.99 \Rightarrow$ & 0.98 ᄃ & $0.96 \Rightarrow$ & 0.95 そ & 0.93 \ & 0.91 \\
\hline Jihovýchod & & $1.00 \Rightarrow$ & $0.98 \Rightarrow$ & $0.98 \Rightarrow$ & $0.98 \Rightarrow$ & $1.00 \Rightarrow$ & 1.11 & Sardegna $\Rightarrow$ & $0.99 \Rightarrow$ & 0.96 ह & $0.97 \Rightarrow$ & $0.98 \Rightarrow$ & $0.98 \Rightarrow$ & 1.03 \\
\hline Strední More & & $1.00 \Rightarrow$ & $0.98 \Rightarrow$ & $0.95 \Rightarrow$ & $0.97 \Rightarrow$ & $1.00 \Rightarrow$ & 1.11 & Kypros & $1.00 \Rightarrow$ & 0.97 ら & $0.97 \Rightarrow$ & $0.95 \sqrt{2}$ & 0.91 凤 & 0.92 \\
\hline Moravskos| & & $1.03 \Rightarrow$ & $1.01 \Rightarrow$ & $1.00 \Rightarrow$ & $1.01 \Rightarrow$ & 1.03 亿 & 1.16 & Latvija & 1.00 そ & $0.89 \sqrt{2}$ & 0.86 \& & 0.89 乙 & $0.93 \Rightarrow$ & 1.03 \\
\hline Hovedstade & $\Rightarrow$ & $1.02 \Rightarrow$ & $0.99 \Rightarrow$ & $0.96 \Rightarrow$ & 0.95 そ & $0.95 \Rightarrow$ & 0.98 & Lietuva $(N U \Rightarrow$ & 0.99 ل & $0.92 \sqrt{2}$ & 0.89 そ & $0.93 \Rightarrow$ & $0.95 \Rightarrow$ & 1.08 \\
\hline Sjælland & $\Rightarrow$ & $0.99 \Rightarrow$ & $0.97 \Rightarrow$ & $0.95 \sqrt{2}$ & $0.95 \sqrt{2}$ & $0.93 \Rightarrow$ & 0.95 & Luxembourş $\Rightarrow$ & $0.99 \Rightarrow$ & 1.02 & $1.02 \Rightarrow$ & $1.01 \Rightarrow$ & $1.02 \Rightarrow$ & 1.03 \\
\hline Syddanmarl & $\Rightarrow$ & $1.01 \Rightarrow$ & $0.97 \sqrt{\checkmark}$ & $0.94 \sqrt{7}$ & $0.95 \sqrt{2}$ & $0.94 \Rightarrow$ & 0.95 & Közép-Mag) $\Rightarrow$ & $1.00 \Rightarrow$ & 0.97 ᄃ & $0.95 \Rightarrow$ & $0.96 \Rightarrow$ & 0.98 个 & 1.14 \\
\hline Midfyy lland & $\Rightarrow$ & $1.02 \Rightarrow$ & $0.98 \Rightarrow$ & $0.95 \Longleftrightarrow$ & $0.95 \checkmark$ & $0.94 \Rightarrow$ & 0.96 & Közép-Dunáa & 0.98 \ & $0.93 \sqrt{2}$ & $0.93 \Rightarrow$ & $0.96 \Rightarrow$ & 0.96 亿 & 1.15 \\
\hline Nordjy lland & $\Rightarrow$ & $1.02 \Rightarrow$ & $0.98 \Rightarrow$ & $0.96 \Rightarrow$ & $0.95 \Rightarrow$ & $0.95 \Rightarrow$ & 0.97 & Ny ugat-Dun $\Rightarrow$ & $0.98 \sqrt{7}$ & $0.94 \sqrt{ }$ & $0.93 \Rightarrow$ & $0.95 \Rightarrow$ & 0.97 乞 & 1.13 \\
\hline Stuttgart & $\Rightarrow$ & $1.01 \Rightarrow$ & $1.01 \Rightarrow$ & $1.01 \Rightarrow$ & $1.03 \Rightarrow$ & $1.03 \Rightarrow$ & 1.07 & Dél-Dunántú $\Rightarrow$ & $1.00 \Rightarrow$ & 1.01 ら & $1.03 \Rightarrow$ & $1.00 \Rightarrow$ & 1.02 个 & 1.24 \\
\hline Karlsruhe & $\Rightarrow$ & $1.02 \Rightarrow$ & $1.00 \Rightarrow$ & $1.00 \Rightarrow$ & $1.02 \Rightarrow$ & $1.03 \Rightarrow$ & 1.05 & Észak-Magj $\Rightarrow$ & $0.98 \Rightarrow$ & 0.96 ह & $0.96 \Rightarrow$ & $0.96 \Rightarrow$ & 0.97 乞 & 1.26 \\
\hline Freiburg & $\Rightarrow$ & $1.01 \Rightarrow$ & $1.01 \Rightarrow$ & $1.02 \Rightarrow$ & $1.04 \Rightarrow$ & $1.04 \Rightarrow$ & 1.05 & Észak-Alfölc $\Rightarrow$ & $0.98 \Rightarrow$ & 0.95 Б & $0.97 \Rightarrow$ & $0.99 \Rightarrow$ & 1.03 亿 & 1.28 \\
\hline Tübingen & $\Rightarrow$ & $1.01 \Rightarrow$ & $1.01 \Rightarrow$ & $1.02 \Rightarrow$ & $1.05 \Rightarrow$ & $1.05 \Rightarrow$ & 1.08 & Dél-Alföld $\Rightarrow$ & $0.99 \Leftrightarrow$ & 0.97 ら & $0.99 \Rightarrow$ & $0.99 \Leftrightarrow$ & 1.02 个 & 1.24 \\
\hline Oberbay ern & $\Rightarrow$ & $1.01 \Rightarrow$ & $1.02 \Rightarrow$ & $1.02 \Rightarrow$ & $1.04 \Rightarrow$ & $1.05 \Rightarrow$ & 1.09 & Malta & $1.01 \Rightarrow$ & 1.01 द & $1.02 \Rightarrow$ & $1.05 \Rightarrow$ & 1.07 个 & 1.23 \\
\hline Niederbayel & & $1.00 \Rightarrow$ & $0.99 \Rightarrow$ & $1.02 \Rightarrow$ & $1.03 \Rightarrow$ & $1.03 \Rightarrow$ & 1.07 & Groningen $\Rightarrow$ & $1.01 \Rightarrow$ & 1.00 ह & $0.99 \Rightarrow$ & $0.98 \Rightarrow$ & $0.98 \Rightarrow$ & 0.96 \\
\hline Oberpfalz & $\Rightarrow$ & $1.03 \Rightarrow$ & $1.01 \Rightarrow$ & $1.01 \Rightarrow$ & $1.03 \Rightarrow$ & $1.03 \Rightarrow$ & 1.06 & Friesland ( $\mathrm{N} \Rightarrow$ & $1.02 \Rightarrow$ & 1.02 & $0.98 \Rightarrow$ & $0.98 \Rightarrow$ & $0.98 \Rightarrow$ & 1.01 \\
\hline Oberfranken & $\Rightarrow$ & $1.02 \Rightarrow$ & $1.01 \Rightarrow$ & $1.02 \Rightarrow$ & $1.07 \Rightarrow$ & $1.08 \Rightarrow$ & 1.10 & Drenthe & $1.01 \Rightarrow$ & 1.01 ᄃ & $0.98 \Rightarrow$ & $0.96 \Rightarrow$ & $0.98 \Rightarrow$ & 1.02 \\
\hline Mittelfranker & $\Rightarrow$ & $1.03 \Rightarrow$ & $1.03 \Rightarrow$ & $1.04 \Rightarrow$ & $1.07 \Rightarrow$ & $1.07 \Rightarrow$ & 1.08 & Overijssel $\Rightarrow$ & $1.02 \Rightarrow$ & 1.01 ? & $0.98 \Rightarrow$ & $0.98 \Rightarrow$ & $0.97 \Leftrightarrow$ & 0.99 \\
\hline Unterfranker & & $1.02 \Rightarrow$ & $1.00 \Rightarrow$ & $1.03 \Rightarrow$ & $1.05 \Rightarrow$ & $1.05 \Rightarrow$ & 1.07 & Gelderland $\Rightarrow$ & $1.01 \Rightarrow$ & $1.00 \sqsubseteq$ & $0.98 \Rightarrow$ & $0.97 \Rightarrow$ & $0.97 \Rightarrow$ & 0.99 \\
\hline Schwaben & $\Rightarrow$ & $1.02 \Rightarrow$ & $1.02 \Rightarrow$ & $1.04 \Rightarrow$ & $1.05 \Rightarrow$ & $1.06 \Rightarrow$ & 1.09 & Flevoland $\Rightarrow$ & $1.03 \Rightarrow$ & 1.04 & $0.99 \Rightarrow$ & $0.98 \Rightarrow$ & $0.98 \Rightarrow$ & 0.99 \\
\hline Berlin & $\Rightarrow$ & $1.01 \Rightarrow$ & $1.05 \Rightarrow$ & $1.06 \Rightarrow$ & $1.08 \Rightarrow$ & 1.10 仓 & 1.17 & Utrecht & $1.01 \Rightarrow$ & 1.01 다 & $0.98 \Rightarrow$ & $0.97 \Rightarrow$ & $0.98 \Rightarrow$ & 0.99 \\
\hline Brandenburs & $\Rightarrow$ & $1.03 \Rightarrow$ & $1.04 \Rightarrow$ & $1.06 \Rightarrow$ & $1.08 \Rightarrow$ & $1.08 \Rightarrow$ & 1.12 & Noord-Hollaı $\Rightarrow$ & $1.02 \Rightarrow$ & 1.02 द & $0.99 \Rightarrow$ & $0.98 \Rightarrow$ & $0.98 \Rightarrow$ & 1.01 \\
\hline Bremen & $\Rightarrow$ & $1.00 \Rightarrow$ & $1.00 \Rightarrow$ & $1.03 \Rightarrow$ & $1.05 \Rightarrow$ & $1.06 \Rightarrow$ & 1.12 & Zuid-Hollanc $\Rightarrow$ & $1.01 \Rightarrow$ & 1.01 Б & $0.98 \Rightarrow$ & $0.97 \Rightarrow$ & $0.97 \Rightarrow$ & 0.98 \\
\hline Hamburg & $\Rightarrow$ & $1.01 \Rightarrow$ & $1.02 \Rightarrow$ & $1.03 \Rightarrow$ & $1.06 \Rightarrow$ & $1.06 \Rightarrow$ & 1.10 & Zeeland $\Rightarrow$ & $1.01 \Rightarrow$ & 1.03 Б & $1.00 \Rightarrow$ & $0.99 \Rightarrow$ & $1.01 \Rightarrow$ & 1.02 \\
\hline Darmstadt & $\Rightarrow$ & $1.02 \Rightarrow$ & $1.02 \Rightarrow$ & $1.03 \Rightarrow$ & $1.05 \Rightarrow$ & $1.05 \Rightarrow$ & 1.07 & Noord-Brab: $\Rightarrow$ & $1.02 \Rightarrow$ & 1.01 द & $0.99 \Rightarrow$ & $0.98 \Rightarrow$ & $0.99 \Rightarrow$ & 1.02 \\
\hline Gießen & $\Rightarrow$ & $1.01 \Rightarrow$ & $1.02 \Rightarrow$ & $1.01 \Rightarrow$ & $1.04 \Rightarrow$ & $1.04 \Rightarrow$ & 1.07 & Limburg (NLC) & $1.02 \Rightarrow$ & 1.01 ら & $0.98 \Rightarrow$ & $0.98 \Rightarrow$ & $1.00 \Rightarrow$ & 1.02 \\
\hline Kassel & $\Rightarrow$ & $1.01 \Rightarrow$ & $1.02 \Rightarrow$ & $1.04 \Leftrightarrow$ & $1.07 \Rightarrow$ & $1.07 \Rightarrow$ & 1.11 & Burgenland $\Rightarrow$ & $1.00 \Rightarrow$ & 0.99 द & $1.00 \Rightarrow$ & $0.99 \Rightarrow$ & $0.99 \Leftrightarrow$ & 1.00 \\
\hline Mecklenbur! & $\Rightarrow$ & $1.04 \Rightarrow$ & $1.06 \Rightarrow$ & $1.08 \Rightarrow$ & $1.09 \Rightarrow$ & 1.08 令 & 1.13 & Niederösterr $\Rightarrow$ & $1.01 \Rightarrow$ & 1.00 & $1.01 \Rightarrow$ & $1.01 \Rightarrow$ & $1.02 \Rightarrow$ & 1.04 \\
\hline Braunschwe & & $1.00 \Rightarrow$ & $1.02 \Rightarrow$ & $1.04 \Rightarrow$ & $1.07 \Rightarrow$ & $1.06 \Rightarrow$ & 1.09 & Wien & $1.01 \Rightarrow$ & 1.01 다 & $1.02 \Rightarrow$ & $1.02 \Rightarrow$ & $1.02 \Rightarrow$ & 1.01 \\
\hline Hannover & $\Rightarrow$ & $1.01 \Rightarrow$ & $1.01 \Rightarrow$ & $1.02 \Rightarrow$ & $1.04 \Rightarrow$ & $1.07 \Leftrightarrow$ & 1.07 & Kärnten & $1.02 \Rightarrow$ & 1.01 द & $1.02 \Leftrightarrow$ & $1.02 \Rightarrow$ & $1.02 \Rightarrow$ & 1.05 \\
\hline Lüneburg & $\Rightarrow$ & $1.01 \Rightarrow$ & $1.04 \Rightarrow$ & $1.05 \Rightarrow$ & $1.07 \Rightarrow$ & $1.07 \Rightarrow$ & 1.10 & Steiermark $\Rightarrow$ & $1.01 \Rightarrow$ & 1.00 द & $1.01 \Rightarrow$ & $1.02 \Rightarrow$ & $1.01 \Rightarrow$ & 1.03 \\
\hline Weser-Ems & $\Rightarrow$ & $1.01 \Rightarrow$ & $1.02 \Rightarrow$ & $1.04 \Rightarrow$ & $1.07 \Rightarrow$ & $1.07 \Leftrightarrow$ & 1.11 & Oberösterrei $\lesseqgtr$ & $1.02 \Rightarrow$ & 1.01 Б & $1.02 \Rightarrow$ & $1.02 \Rightarrow$ & $1.03 \Rightarrow$ & 1.04 \\
\hline Düsseldorf & $\Rightarrow$ & $1.01 \Rightarrow$ & $1.01 \Rightarrow$ & $1.02 \Rightarrow$ & $1.04 \Rightarrow$ & $1.04 \Rightarrow$ & 1.08 & Salzburg $\Rightarrow$ & $1.01 \Rightarrow$ & 1.01 Б & $1.01 \Rightarrow$ & $1.02 \Rightarrow$ & $1.04 \Rightarrow$ & 1.04 \\
\hline Köln & $\Rightarrow$ & $1.01 \Rightarrow$ & $1.01 \Rightarrow$ & $1.02 \Rightarrow$ & $1.04 \Rightarrow$ & $1.04 \Rightarrow$ & 1.09 & Tirol & $1.01 \Rightarrow$ & 1.01 ᄃ & $1.01 \Rightarrow$ & $1.01 \Rightarrow$ & $1.03 \Rightarrow$ & 1.04 \\
\hline Münster & $\Rightarrow$ & $1.01 \Rightarrow$ & $1.01 \Rightarrow$ & $1.03 \Rightarrow$ & $1.05 \Rightarrow$ & $1.05 \Rightarrow$ & 1.07 & Vorarlberg $\Rightarrow$ & $1.01 \Rightarrow$ & 1.00 ᄃ & $1.01 \Rightarrow$ & $1.02 \Rightarrow$ & $1.03 \Rightarrow$ & 1.06 \\
\hline Detmold & $\Rightarrow$ & $1.02 \Rightarrow$ & $1.00 \Rightarrow$ & $1.01 \Leftrightarrow$ & $1.04 \Rightarrow$ & $1.06 \Rightarrow$ & 1.08 & Lódzkie (NLら & $1.04 \Rightarrow$ & 1.03 ᄃ & $1.03 \Rightarrow$ & $1.05 \Rightarrow$ & 1.03 它 & 1.17 \\
\hline Arnsberg & $\Rightarrow$ & $1.02 \Rightarrow$ & $1.02 \Rightarrow$ & $1.03 \Rightarrow$ & $1.06 \Rightarrow$ & $1.07 \Leftrightarrow$ & 1.10 & Mazowiecki $\lesseqgtr$ & $1.06 \Rightarrow$ & 1.06 द & $1.05 \Rightarrow$ & $1.07 \Rightarrow$ & 1.08 个 & 1.15 \\
\hline Koblenz & $\Rightarrow$ & $1.00 \Rightarrow$ & $0.99 \Rightarrow$ & $1.02 \Rightarrow$ & $1.03 \Rightarrow$ & $1.03 \Rightarrow$ & 1.05 & Malopolskie $\Rightarrow$ & $1.05 \Rightarrow$ & 1.03 ᄃ & $1.02 \Rightarrow$ & $1.02 \Rightarrow$ & 1.02 亿 & 1.13 \\
\hline Trier & $\Rightarrow$ & $1.03 \Rightarrow$ & $1.02 \Rightarrow$ & $1.04 \Rightarrow$ & $1.03 \Rightarrow$ & $1.04 \Rightarrow$ & 1.07 & Slaskie & $1.04 \Rightarrow$ & 1.06 ह & $1.05 \Rightarrow$ & $1.06 \Rightarrow$ & 1.06 个 & 1.19 \\
\hline Rheinhesse & $\Rightarrow$ & $1.01 \Rightarrow$ & $1.00 \Rightarrow$ & $1.01 \Rightarrow$ & $1.02 \Rightarrow$ & $1.03 \Rightarrow$ & 1.05 & Lubelskie ( $\Rightarrow$ & $0.99 \Rightarrow$ & 0.98 & $0.99 \Rightarrow$ & $1.00 \Rightarrow$ & $1.01 \Rightarrow$ & 1.06 \\
\hline Saarland & $\Rightarrow$ & $1.02 \Rightarrow$ & $1.00 \Rightarrow$ & $1.02 \Rightarrow$ & $1.03 \Rightarrow$ & $1.04 \Rightarrow$ & 1.10 & Podkarpack $\Rightarrow$ & $1.02 \Rightarrow$ & 1.03 द & $1.02 \Rightarrow$ & $1.01 \Rightarrow$ & $1.01 \Rightarrow$ & 1.11 \\
\hline Dresden & $\Rightarrow$ & $1.03 \Rightarrow$ & $1.04 \Rightarrow$ & $1.07 \Rightarrow$ & $1.09 \Rightarrow$ & 1.09 令 & 1.14 & Swietokrzys $\Rightarrow$ & $1.04 \Rightarrow$ & 1.02 द & $1.01 \Rightarrow$ & $1.00 \Rightarrow$ & $1.01 \Rightarrow$ & 1.09 \\
\hline Chemnitz & $\Rightarrow$ & $1.03 \Rightarrow$ & $1.03 \Rightarrow$ & $1.06 \Rightarrow$ & $1.08 \Rightarrow$ & 1.09 亿 & 1.15 & Podlaskie (N $\Rightarrow$ & $1.04 \Rightarrow$ & 1.04 ら & $0.99 \Rightarrow$ & $1.02 \Rightarrow$ & $1.04 \Rightarrow$ & 1.12 \\
\hline Leipzig & $\Rightarrow$ & $1.05 \Rightarrow$ & $1.07 \Rightarrow$ & $1.09 \Rightarrow$ & $1.11 \Rightarrow$ & 1.11 亿 & 1.17 & Wielkopolsk $\Rightarrow$ & $1.05 \Rightarrow$ & 1.05 ᄃ & $1.05 \Rightarrow$ & $1.05 \Rightarrow$ & 1.06 亿 & 1.20 \\
\hline Sachsen-An & & $1.03 \Rightarrow$ & $1.05 \Rightarrow$ & $1.08 \Rightarrow$ & $1.11 \Rightarrow$ & 1.10 亿 & 1.12 & Zachodniopı $\leftrightharpoons$ & $1.04 \Rightarrow$ & 1.06 ら & $1.03 \Rightarrow$ & $1.04 \Rightarrow$ & 1.08 合 & 1.22 \\
\hline Schleswig-t & & $1.01 \Rightarrow$ & $1.01 \Rightarrow$ & $1.02 \Rightarrow$ & $1.04 \Rightarrow$ & $1.05 \Rightarrow$ & 1.08 & Lubuskie $\Rightarrow$ & $1.02 \Rightarrow$ & 1.01 द & $1.02 \Rightarrow$ & $1.03 \Rightarrow$ & 1.03 个 & 1.17 \\
\hline
\end{tabular}

Sources: [13] 


\section{\#3/2018 URBAN CHALLENGES}

\section{REFERENCES}

[1] http://www.dictionary.com/browse/resilience

[2] https://dexonline.ro/definitie/rezilien\%C8\%9B\%C4\%83

[3] Simmie J., Martin R. (2010), "The economic resilience of regions: towards and evolutionary approach", Cambridge Journal of Regions, Economy and Society 3, 27-43. doi:10.1093/cjres/rsp029.

[4] Martin, R. (2012). "Regional economic resilience, hysteresis and recessionary shocks". Journal of Economic Geography, 12(1), 1-32.

[5] Bosher L., Coaffee J. (2008), "International Perspectives on Urban Resilience", January 2008, Urban Design and Planning 161(4):145-146, DOI10.1680/udap.2008.161.4.145.

[6] Swanstrom, T. (2008), "Regional Resilience: A Critical Examination of the Ecological Framework", Working Paper 2008-7. Berkeley, CA: Macarthur Foundation Research Network on Building Resilient Regions, Institute for Urban and Regional Development, University of California.

[7] Hill, E. W., Wial, H. and Wolman, H. (2008), "Exploring Regional Resilience", Working Paper 2008-04. Berkeley, CA: Macarthur Foundation Research Network on Building Resilient Regions, Institute for Urban and Regional Development, University of California.

[8] Alberti, M., Marzluff J., Shulenberger E., Bradley B., Ryan C., Zumbrunnen C. 2003. "Integrating humans into ecology: opportunities and challeneges for studying urban ecosystems." Bioscience. 53 (12): 1169-1179.

[9] Foster, K. A. (2007), "A Case Study Approach to Understanding Regional Resilience". Working Paper 2007- 08, Institute of Urban and Regional Development, University of California, Berkeley.

[10] http://ssgm.bellschool.anu.edu.au/sites/default/files/publications/attachments/201512/Feeny Household2013 0.pdf

[11] Sotarauta, M. (2005). "Tales of resilience from two Finnish cities: Self-renewal capacity at the heart of strategic adaptation", in C. Duke, M. Osborne, \& B. Wilson (Eds.), Rebalancing the social and economic learning, partnership and place. Niace: Leicester.

[12] Peiwen Lu, Dominic Stead (2013), "Understanding the notion of resilience in spatial planning: A case study of Rotterdam", The Netherlands.

[13] www.eurostat.com

[14] Zaman Gh., Georgescu G. (2015), "Regional aspects of economic resilience in Romania, during post-accesion period", http://revecon.ro/articles/2015-1/2015-1-0.pdf.

\section{Article distributed under a Creative Commons Attribution- NonCommercial-NoDerivatives 4.0 International License (CC BY-NC-ND).}

Received: May 14, 2018

Accepted: May 20, 2018. 